\title{
RELATO TÉCNICO: PERCEPÇÃO DE FREQUENTADORES SOBRE ESPAÇO, ESTRUTURA E GESTÃO DO PARQUE DA ÁGUA BRANCA, SP.
}

Milena de Moura Régis

\author{
Ana Paula do Nascimento Lamano-Ferreira ${ }^{1}$
}

Heidy Rodriguez Ramos ${ }^{2}$

\begin{abstract}
RESUMO
Conhecer a relação do homem com a natureza torna-se cada vez mais necessário, para que a partir de sua percepção, se obtenha dados que possam auxiliar na elaboração de projetos e programas de gestão e educação ambiental. A percepção ambiental passa a ser um instrumento científico significativo na tomada de decisões, sobre medidas mitigadoras por parte de gestores ambientais. É sob esse enfoque, que o presente relato objetivou levantar a percepção ambiental de frequentadores do Parque da Água Branca, localizado na região oeste da Cidade de São Paulo. Para o levantamento de dados, foram entrevistados 28 frequentadores do Parque, sendo 14 mulheres e 14 homens. Diante das respostas dos entrevistados, é possível afirmar que a aplicação de questionários sobre percepção permite a compreensão dos conflitos do espaço estudado, tornando-se uma ferramenta de transmissão da opinião dos frequentadores para os gestores do parque e para o poder público, assim auxiliando na tomada de decisões sobre a gestão desse espaço.
\end{abstract}

Palavras-chave: Percepção Ambiental, Áreas Verdes, Planejamento Urbano.

\section{INTRODUÇÃO}

A relação do homem com o meio ambiente acontece desde o surgimento do primeiro Homo sapiens no Planeta Terra, mas os limites da natureza eram respeitados. Com o passar dos anos e a com a evolução intelectual, a humanidade passou a modificar o ambiente em que vivia, fazendo uso dos recursos naturais

\footnotetext{
${ }^{1}$ UNINOVE - Universidade Nove de Julho. E-mail apbnasci@yahoo.com.br

${ }^{2}$ UNINOVE - Universidade Nove de Julho. E-mail heidyr@gmail.com
} 
desordenadamente (MAIA et al., 2014). No entanto, nas últimas décadas os seres humanos estão se conscientizando e passaram-se a se preocupar com as questões relacionadas ao meio ambiente. Com isso, vários setores da sociedade vêm discutindo o desenvolvimento de atividades e projetos que sensibilizem as populações a modificarem suas atitudes, adotando posturas mais sustentáveis em busca do equilíbrio ambiental (FRANÇA; GUIMARÃES, 2014).

As discussões sobre os aspectos ambientais vêm se tornando cada vez mais fundamentais, pois reflete a percepção que o ser humano tem em relação à natureza, sendo uma grande contribuição, no destaque global de questões relacionadas à preservação ambiental (SUESS et al., 2013).

A afinidade inata em relação ao meio ambiente, desperta o desejo humano de restabelecer a ligação com a natureza, assim influenciando na escolha de seus locais verdes preferidos (JIM; CHEN, 2006). Nesse sentido, a percepção do homem em relação à natureza, muitas vezes ocorre como uma resposta cognitiva às experiências pessoais, vividas e relacionadas ao meio ambiente (LO; JIM, 2010). Sendo assim, a percepção ambiental passa a ser um instrumento científico muito significativo na tomada de decisões sobre medidas mitigadoras e sobre estratégias de gestão por parte de gestores ambientais (SILVA, 2012). É sob esse enfoque que o presente relato técnico objetiva levantar a percepção dos frequentadores em relação ao Parque da Água Branca, localizado na região oeste da Cidade de São Paulo.

Para tais levantamentos o relato técnico foi guiado pela seguinte pergunta de pesquisa: i) Qual é a percepção ambiental dos frequentadores do Parque da Água Branca em relação às melhorias a serem realizadas na gestão desse espaço?

\section{OBJETIVO}

O objetivo deste trabalho foi relatar a percepção de frequentadores do Parque Água Branca, sobre seu espaço, estrutura e gestão.

\section{METODOLOGIA}




\subsection{Local de estudo}

O presente estudo foi realizado no Parque Dr. Fernando da Costa, mais conhecido como Parque da Água Branca, localizado na Avenida Francisco Matarazzo, número 455, no bairro da Barra Funda, na Zona Oeste do Município de São Paulo - SP. O parque está aberto ao público diariamente no período das 06h00m. às 22h00m. (SMA, 2014). Criado em 1929, o Parque da Água Branca dispõe de um espaço de 137 mil metros quadrados e oferece atrações para todas as idades (PGESP, 2014).

Para as crianças, o parque oferece: brinquedoteca; espaço de leitura infantil, parquinhos com balanços, gangorras, diversos brinquedos e etc. Já a terceira idade, pode usufruir da Praça do Idoso, onde estão disponíveis aparelhos para a prática de ginástica, também podem praticar a ginástica antiestresse e yoga (SMA, 2014).

O visitante do Parque da Água Branca, ainda tem a oportunidade de ter contato direto com a natureza, com os animais, pois o parque abriga diversas espécies de aves (pavões, gansos, patos, galinhas e galos) e felinos que ficam soltos pelo perímetro, e peixes (como carpas) e repteis (como tartarugas) que habitam os tanques espalhados pelo local (SMA, 2014).

\subsection{Coleta de Dados}

Os dados foram coletados por meio de entrevistas (LIU et al., 2010), guiadas por um roteiro (MATOS; GOMES, 2011), semiaberto (MACHADO-FILHO et al., 2014; VERGARA, 2006), composto de perguntas abertas e de múltipla escolha livre (MACHADO-FILHO et al., 2014), que segue uma ordem lógica, começando com questões mais gerais e se tornando mais especificas, o que permite ao entrevistado passar facilmente de uma resposta a outra (VERGARA, 2006).

O roteiro de entrevista foi adaptado de Teramussi, 2008. Foram adaptadas 29 questões que permitiram identificar variaveis sócio demográficas (LIU, et al, 2010; LAFORTEZZA, 2009), tais como: nome; idade; nível de escolaridade e sexo. Além 
Objetivando traçar o perfil dos respondentes foram realizadas perguntas sobre o nível de escolaridade e assim como descreve Suess et al. (2013), as informações sobre o nível de escolaridade relatadas pelos entrevistados, foram agrupados nas seguintes categorias: Ensino Fundamental incompleto; Ensino Fundamental completo; Ensino Médio incompleto; Ensino Médio completo; Ensino Superior incompleto; Ensino Superior Completo. Apenas duas mulheres declaram: pós-graduação completa e mestrado completo, então por conveniência, optou-se por agrupar tais declarações junto ao grupo de Ensino Superior Completo.

Tabela 1. Perfil socioambiental da população estudada no Parque da Água Branca, São Paulo, SP.

\begin{tabular}{lllll}
\hline VÁRIAVEIS & HOMENS & \multicolumn{3}{l}{ MULHERES } \\
\hline FAIXA ETÁRIA & $\mathrm{N}=14$ & $\%$ & $\mathrm{~N}=14$ & $\%$ \\
19 a 29 anos & 6 & $42,85 \%$ & 7 & $50 \%$ \\
30 a 39 anos & 4 & $28,57 \%$ & 2 & $14,28 \%$ \\
40 a 49 anos & 3 & $21,42 \%$ & 0 & $0 \%$ \\
50 anos ou mais & 1 & $7,14 \%$ & 5 & $35,71 \%$ \\
NIVEL DE ESCOLARIDADE & & & & \\
Ensino Fundamental incompleto & 1 & $7,14 \%$ & 1 & $7,14 \%$ \\
Ensino Fundamental completo & 0 & $0 \%$ & 0 & $0 \%$ \\
Ensino Médio incompleto & 0 & $0 \%$ & 1 & $7,14 \%$ \\
Ensino Médio completo & 3 & $21,42 \%$ & 6 & $42,85 \%$ \\
Ensino Superior incompleto & 6 & $42,85 \%$ & 1 & $7,14 \%$ \\
Ensino Superior Completo & 4 & $28,57 \%$ & 5 & $35,71 \%$ \\
\hline
\end{tabular}

Fonte: Elaborado pelos autores a partir dos dados levantados.

Quando perguntados sobre o que mais gostam no Parque da Água Branca, tanto homens quanto as mulheres relacionaram o contato com a natureza; a interação com os animais, do ar puro, a sensação de tranquilidade; a paisagem, a infraestrutura como equipamentos de ginasticas, da possibilidade de realizar atividades físicas, principalmente caminhadas (sendo esta a prática mais mencionada dentre os respondentes de ambos os gêneros). Além de atribuírem ao parque sensações como sossego e perceberem esse espaço como um local de refúgio do caos urbano, como nas respostas a seguir: 
Quadro 1. Respostas à pergunta: $O$ que você mais gosta no Parque da Água Branca?

\begin{tabular}{|l|l|}
\hline HOMENS & MULHERES \\
\hline $\begin{array}{l}\text { "Do ambiente saudável, embora a gente esteja } \\
\text { no meio de uma avenida as árvores fogem do } \\
\text { contexto"; }\end{array}$ & "De me sentir fora da cidade" \\
"Eu gosto das árvores, de ser um lugar & "É a tranquilidade, é você poder sentar, ficar \\
tranquilo assim, desligar um pouco do transito, \\
$\begin{array}{l}\text { coisas do tipo, eu venho aqui só para dar uma } \\
\text { relaxada"; }\end{array}$
\end{tabular}

Fonte: Elaborado pelos autores a partir dos dados levantados.

Tais resultados são semelhantes aos obtidos por Suess et al (2013), em seu estudo realizado no Lago do Abreu em Formosa-GO. Entretanto essas informações foram muito além do que se esperava obter com esse questionamento, pois estimava-se que os respondentes elencariam os equipamentos físicos do parque ou falariam da infraestrutura, no entanto as respostas obtidas já permitiram uma primeira análise da percepção ambiental dos frequentadores em relação ao Parque da Água Branca.

Em contrapartida, quando questionados sobre o que menos gostam no parque, os respondentes foram mais específicos, na figura 1 é possível visualizar as respostas. Muitos afirmaram não haver nada que não gostam no parque $(42,85 \%$ dos homens e $21,42 \%$ das mulheres). Alguns apontaram as galinhas soltas pelo parque, como sendo o que menos gostam $(28,57 \%$ dos homens e $14,28 \%$ das mulheres). Enquanto outros listaram a "sujeira; os pombos soltos; a presença de moradores de rua consumindo álcool e feridos; o barulho das crianças; o barulho da Avenida; não ter sorvete, não poder jogar bola e o parque as vezes ficar muito cheio", como aspectos que menos gostam no Parque da Água Branca. 


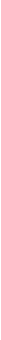

Figura 1. Resposta à questão: O que você menos gosta no Parque da Água Branca

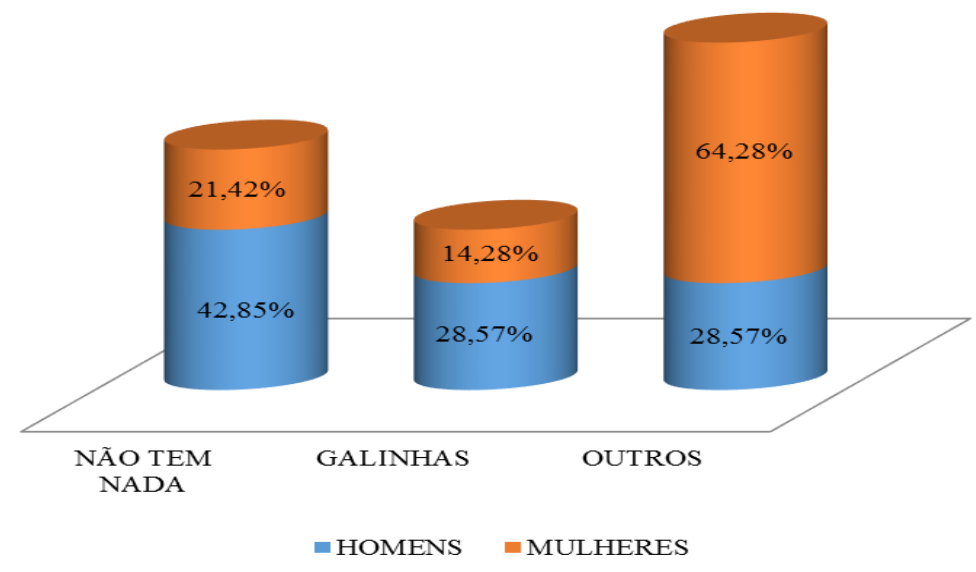

Fonte: Elaborado pelos autores a partir dos dados levantados.

A partir do agrupamento das palavras chave identificadas nas respostas dos entrevistados, dispostas no quadro 2, é possível observar que os respondentes se relacionam e percebem o Parque da Água Branca, como sendo um espaço importante não só para o lazer, mas como um local de refúgio da agitação metropolitana, onde se pode resgatar o contato com a natureza. Nota-se que as descrições que fariam para alguém que nunca visitou o parque, também se assemelham. Desta forma, verifica-se que em suas respostas os entrevistados, trazem uma contextualização do Parque da Água Branca de uma forma muito particular que está totalmente relacionada a sua realidade, com o acesso e com as interações que essas pessoas têm e realizam no parque.

O que confere com os resultados apresentados por Machado-Filho et al (2014), que no estudo sobre percepção ambiental de alunos das salas de inclusão social, na escola Liceu Paraibano, na cidade de João Pessoa, no Estado da Paraíba, os autores relatam que as respostas obtidas trazem o contexto de um meio ambiente na forma mais próxima da realidade do entrevistado, sendo este um espaço do qual ele tem acesso, que ele pode intervir e interagir. E acrescentando as palavras "local" ou "lugar" em suas respostas, o entrevistado remete-se a um ponto específico do espaço geográfico, que fazem parte do seu imaginário perceptivo. 


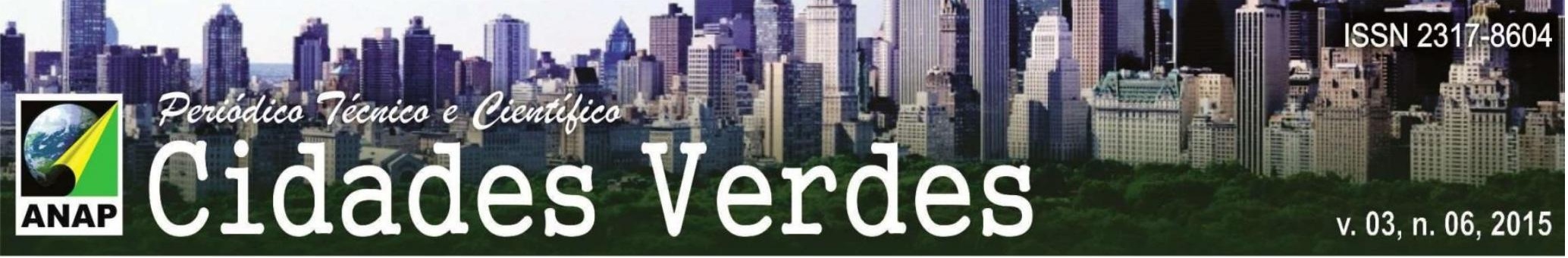

se preocupar com possíveis contaminações oriundas das excreções das aves dentre outras.

\section{REFERÊNCIAS}

CRESWELL, John W. Investigação qualitativa e projeto de pesquisa: escolhendo entre cinco abordagens. 3.ed. Porto Alegre: Penso, 2014.

FRANÇA, Patrícia Auxiliadora Ribeiro; GUIMARÃES, Maria da Glória Vitório. A educação ambiental nas escolas municipais de Manaus (AM): um estudo de caso a partir da percepção dos discentes. Revista Monografias Ambientais, v.13, n.2, p.3128-3138, 2014.

JIM, C. Y.; CHEN, Wendy Y. Perception and attitude of residents toward urban green spaces in Guangzhou (China). Environmental management, v.38, n.3, p.338-349, 2006.

GODOI, Christiane Kleinübing; BANDEIRA-DE-MELO, Rodrigo; SILVA, Aneilson Barbosa (orgs). Pesquisa qualitativa em estudos organizacionais: paradigmas, estratégias, e métodos. 2.ed. São Paulo: Saraiva, 2010.

LAFORTEZZA, Raffaele et al. Benefits and well-being perceived by people visiting green spaces in periods of heat stress. Urban forestry \& Urban greening. V.8, n.2, p.97-108, 2009.

LIU, Jing; OUYANG, Zhiyun; MIAO, Hong. Environmental atitudes of stakeholders and their perceptions regarding protected área-community conflicts: A case study in China. Journal of environmental management, v.91, n.11, p.2254-2262, 2010.

LO, Alex YH; JIM, C. Y. Differential community effects on perception and use of urban greenspace. Cities. v.27, p.430-442, 2010.

MACHADO-FILHO, Hermes de Oliveira et al. Percepção Ambiental de alunos das "Salas de Inclusão" na escola Liceu Paraibano, João Pessoa - PB, no contexto do paradigma da educação inclusiva. Revista do Centro do Ciências Naturais e Exatas - UFSM, Santa Maria. Revista Monografias Ambientais - REMOA, v.13, n.2, p.3255-3264, 2014.

MAIA, Hérika Juliana Linhares et al. Educação ambiental: instrumento de mudança de percepção ambiental de catadores de materiais recicláveis organizados em associação. Revista Monografias Ambientais, v.13, n.13, p. 2797-2806, 2014.

MATOS, Anselmo A.; GOMES, Laura Jane. Participação Social: A interface ausente na área de proteção ambiental Morro do Urubu, Aracaju-Se. Scientia Plena, v.7, n.11, 2011.

MILANO, Camila Boneli de. Análise da percepção ambiental de moradores e visitantes da represa do Broa, Itirapina e Brotas, SP, Brasil. Anais do VII Congresso de Medio Ambiente/AUGM. La Plata. Argentina, 2012.

SMA - Secretaria do Verde e do Maio Ambiente - Parque da Água Branca. Disponível em $<$ http://parqueaguabranca.sp.gov.br/o-parque/> Acesso em 14. nov.2014.

PGESP - Portal do Governo do Estado de São Paulo. Disponível em $<$ http://www.saopaulo.sp.gov.br/conhecasp/turismo parques agua-branca > Acesso em 16. nov.2014. 


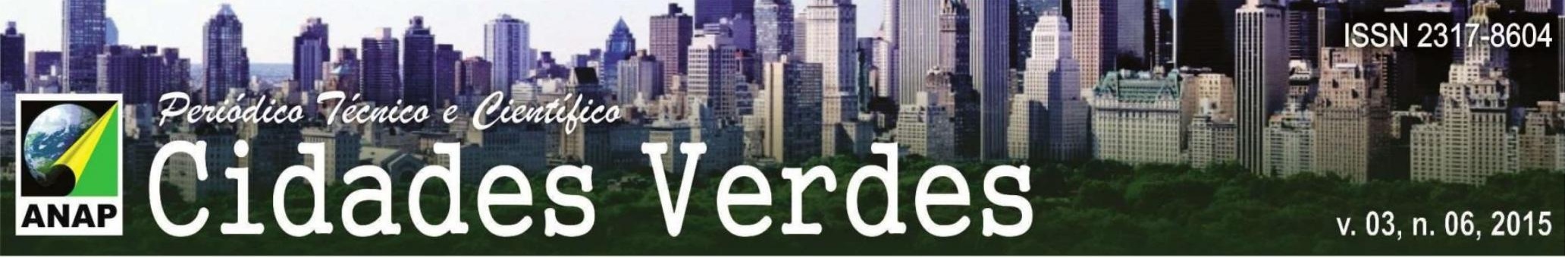

QUEIROZ, Maria Isaura Pereira de. Variações sobre a técnica de gravador no registro da informação viva. São Paulo: CERU e FFLCH/USP, 1983.

SILVA, Angélica dos Santos da. Percepção Ambiental De Frequentadores E Estudo Dos Impactos Do Parque Ecológico Laguna da Jansen, Município De São Luís, MA. In Congresso Brasileiro de Gestão Ambiental, v.3, 2012.

SOUZA, Tayron Juliano et al. Percepção dos frequentadores de área de preservação permanente em Petrolina-PE quanto ao meio ambiente e a degradação ambiental. Revista Seminário De Visu, v.2, n.3, p.317-325, 2012.

SUESS, Rodrigo, Capell; BEZERRA, Rafael Gonçalves; DE CARVALHO SOBRINHO, Hugo. Percepção ambiental de diferentes atores sociais sobre o Lago do Abreu em Formosa - GO. Holos, v.6, p.241-258, 2013.

TERAMUSSI, Thais Moreto. Percepção ambiental de estudantes sobre o Parque Ecológico do Tietê, São Paulo-SP. 2008. Dissertação de mestrado, Universidade de São Paulo, São Paulo, SP, 2008.

VERGARA, Sylvia Constant. Métodos de coleta de dados no campo. 2.ed. São Paulo: Atlas, 2006. 